\title{
APPROXIMATION OF SCOURS USING TERRESTRIAL 3D LASER SCANNING
}

\author{
Andreea Florina Jocea ${ }^{a}$ *, E. G. Crăciun ${ }^{b}$, A. Anton ${ }^{b}$ \\ a, * Technical University of Civil Engineering of Bucharest, Faculty of Geodesy, Surveying and Cadastre Department, Lacul Tei \\ Blvd., no. 122 - 124, RO 020396, sector 2, Bucharest, Romania, e-mail: andreea.jocea@ geodezie.utcb.ro \\ ${ }^{\mathrm{b}}$ Technical University of Civil Engineering of Bucharest, Faculty of Hydrotechnics, Hydraulics and Environmental Department, \\ Lacul Tei Blvd., no. 122 - 124, RO 020396, sector 2, Bucharest, Romania, e-mail: anton@utcb.ro
}

Received: 10.03.2015 / Accepted: 29.03.2015 / Revised: 28.04.2015 / Available online: 31.05.2015

DOI: 10.1515/jaes-2015-0004

KEY WORDS: Scours, Terrestrial Laser Scanning, Point Cloud

\begin{abstract}
:
In designing artwork as bridges, hydraulic calculations have a very important role due to the fact that they are behind their sizing. Bridge designer must therefore possess knowledge of hydrology, hydraulics of bridges and river banks regularization. A problem that arises during the design stage of bridges is the scour phenomenon surrounding bridge pier. Over time, there have been conducted a number of studies which led to the provision of a plurality of mathematical models that are intended scour prediction. In the present article we will present an experimental study to determine the bed profile and measurement of scours products around a pier bridge using 3D terrestrial laser scanner.
\end{abstract}

\section{INTRODUCTION}

\subsection{Basic Concept}

The design of any bridge begins with hydraulic sizing. Hydraulic calculations are necessary for an accurate assessment of bridge stability to determine the foundation type and foundation share. Possible scour that may arise during the operation of the bridge must be considered in this case (Craciun, 2014).

According to (Prendergast, Gavin, 2014) a scour can be defined as the excavation and the removal of the material and banks of streams as a result of an erosion action of the flowing water. A scour hole is defined as depression left behind when sediment is washed away from the riverbed in the vicinity of a structure (Beg, Beg, 2013).

The scour may occur in three forms:

- general scour, which occurs naturally in the river channel and includes aggradation and degradation of the river bed as a result of changes in the hydraulic parameters of the channel form (Forde et al., 1999);

- contraction scour occurs as a result of the reduction in the channel's cross-sectional area that arises due to the construction of structure such as bridge piers and abutments (Briaud et al., 1999);

- local scour occurs around individual piers and abutments (Hamill, 1998).
Over the last three decades the problem of scour has been studied and overviewed in the specialised literature. Also, during these three decades more and more numerical model for scour prediction has been developed (Cao et al., 2015).

However, most of the experiments have been carried out in flumes under idealized conditions, such as steady uniform sediment, simplified geometry, etc. Therefore, their applications to may produce questionable results (Esmaieli et al, 2009).

A more satisfactory approach for further applications in field situations is to simulate accurately the flow field and scouring processes using a 3D numerical model. Modeling 3D flow field and scour hole evolution around a bridge pier is more feasible nowadays because the computational cost and computational time have significantly decreased (Olsen et al, 1999).

Given the importance, hydraulics of bridges research focused on estimating scour depth and their configuration were performed nationally by the Institute for Research and Hydraulics Laboratory of the Technical University of Civil Engineering of Bucharest. The experimental approach, using clear water and water with material transport were chosen for knowledge of the effects of scour on pier bridge, analytical approach instead.

The present article will present an experimental research on contraction and local scour conducted in a channel with variable slope and glass walls (Armfield, 2010) - "Sediment Demonstration Channel" - which is found in Hydraulics

\footnotetext{
* Corresponding author.
} 
Laboratory of the Technical University of Civil Engineering of Bucharest using 3D terrestrial laser scanner.

\subsection{Terrestrial 3D Laser Scanning principle}

3D terrestrial laser scanning, known in the literature as static laser scanning represents modern technology, active and contactless acquisition of spatial data, in the form of point clouds, with speed and high precision. It examines the object space in order to collect information on its surface (shape, size).

The information collected are then used to generate twodimensional representations or three-dimensional designs used in a variety of applications (figure 1) (Jocea et al., 2013).

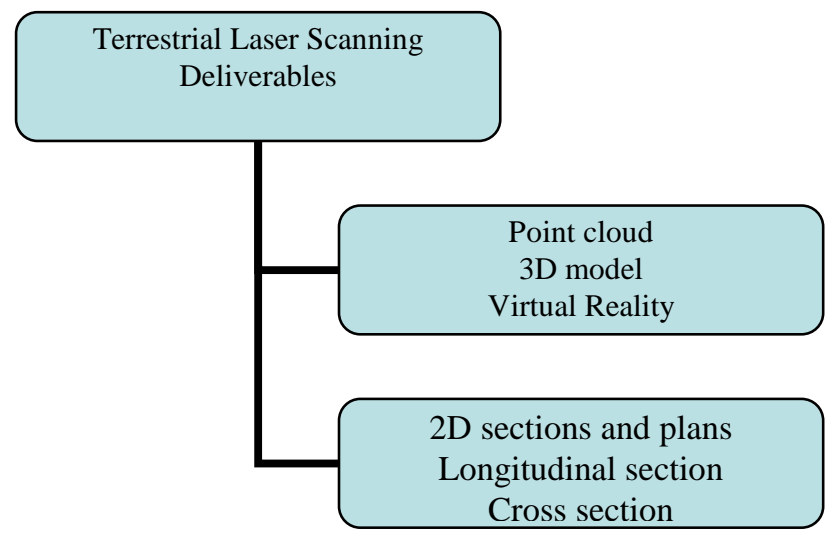

Figure 1. Terrestrial 3D Laser Scanning Deliverables

A terrestrial laser scanner mechanism implies a deflection of the laser beam in two directions - vertical and horizontal - for sampling a given region of the object investigated. The laser beam emitted from the electronic unit strikes the optical element which rotates at high speed.

The beam is reflected by the optical element (which acts as a mirror) and leaves the scanning device with an angle $\beta$. Once the scanner has finished scanning the profile, the top of the scanner rotates at a very small angle $(\alpha)$ around the vertical axis to start sweep profile adjacent profile (figure 2) (Jocea et al., 2013).

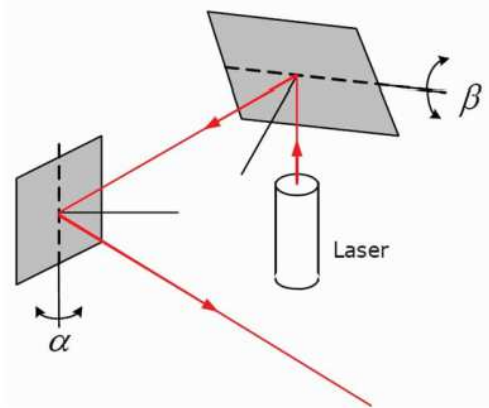

Figure 2. The principle of laser scanning (Staiger, 2007)

\section{EXPERIMENTAL STUDY}

The experiment is based on geometric similarity between a bridge crossing Prut River (in Romania) and canal with glass walls and variable slope existing in the hydraulic laboratory of Technical University of Civil Engineering Bucharest.

The condition of similarity between the two phenomena, where gravity is the dominant force, is the kinematic similarity to conditions to be satisfied the relationship:

$$
F r=i d e m
$$

where: $F r$ is Froude number.

The similarity is starting from current water depth. Prut river water depth is about $7.5 \mathrm{~m}$ and water depth for model is about 3 $\mathrm{cm}$ (Craciun, Anton, 2013).

The advantages of using a channel with glass walls model consist in the ease of modelling of a general situation of scours of the riverbed around cells. The ease of modification the slope of the bottom of the channel and the simulation of lamellar and turbulent flow of water represent other advantages.

The disadvantage lies in the discrepancy between the model and a real situation in terms of wall roughness. Also it needs to take into account that in the experiment it was used clean water.

\subsection{Channel description}

The channel used to demonstrate the process sedimentation consists in four elements (figure 3) (Armfield, 2010):

- The channel with variable slope mounted on a metal frame,

- A sump,

- A water recycling pump

- A pool of tranquillity.

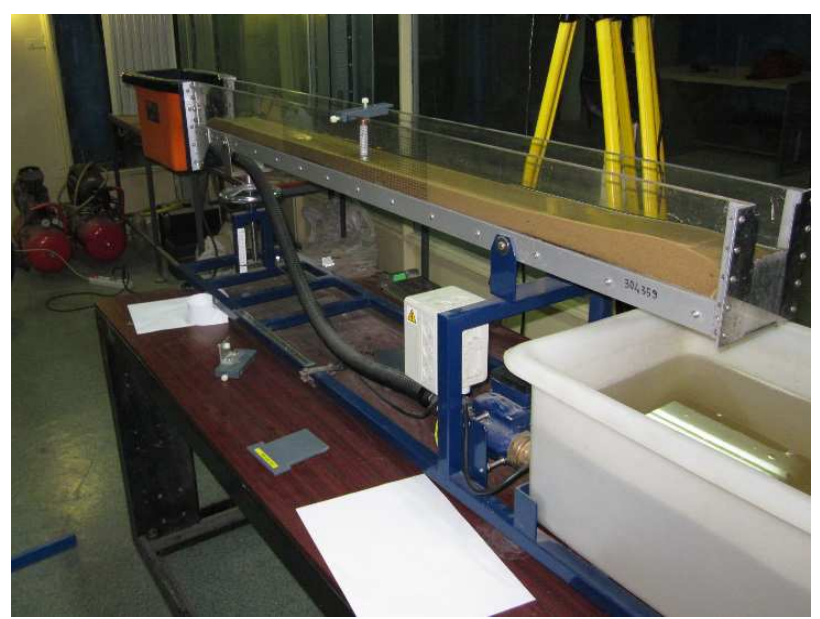

Figure 3. Scheme of sediment transport demo channel (Craciun, 2014)

In order to achieve the similarity about we have mentioned above, the scale report used to perform the laboratory model was $1 / 250$, based on the dimensions of a real bridge.

In reality the width of the bridge pier is $3.40 \mathrm{~m}$. Using the scale factor, it follows that the size of model pier is $1.36 \mathrm{~cm}$. Particle size of channel bed used in experiments was $0.20 \mathrm{~mm}$ (Craciun, Anton, 2013). 
Therefore, measurements made on the model must have a larger precision. Thus, the scanner ScanStation 2 from Leica Geosystems was used for an accurate measurement of scour recorded in laboratory conditions.

\subsection{Leica ScanStation 2 Terrestrial Laser Scanning System}

ScanStation2 scanner (figure 4) from Leica Geosystems (Atlanta, Ga.) is a portable scanning system and can be installed and centred on a point with known coordinate's station or on georeferenced new points.

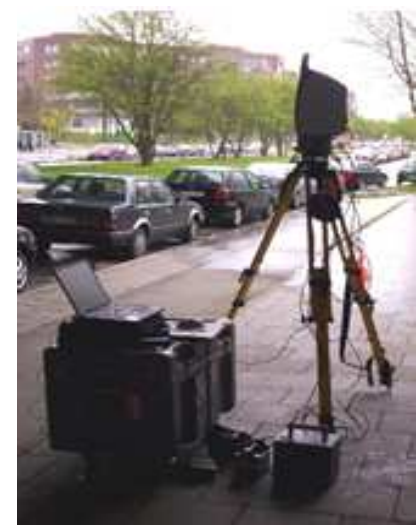

Figure 4. ScanStation 2 laser scanning system (Jocea, 2005)

Field of View (FOV) (figure 5) used to scan is panoramic $\left(360^{\circ}\right.$ on horizontal). The panoramic image taken by the scanner is displayed on a laptop connected to the scanner, and allows the operator to select the region to be scanned.

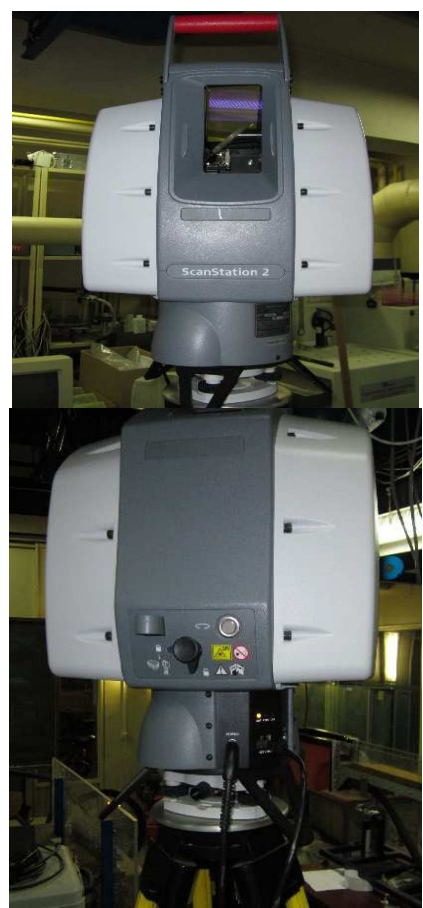

Figure 5. Leica ScanStation 2 - front view (up), rear view (down) (Craciun, 2014)

As a double - pattern window, the angle of view in the vertical plane can be up to $270^{\circ}$ (figure 6).
The order of the scanning is from left to right in the horizontal direction, from the bottom upwards for the main window and from the top downwards for the upper window, in the vertical direction.

\subsection{Data Acquisition}

The Leica ScanStation 2 laser scanner was mounted near the object to be acquired (figure 6). Three artificial targets, mainly used to record scans taken from different positions, were positioned around the channel, so that it covered all three spatial directions $\mathrm{x}, \mathrm{y}$ and $\mathrm{z}$ (Craciun, Anton, 2013).

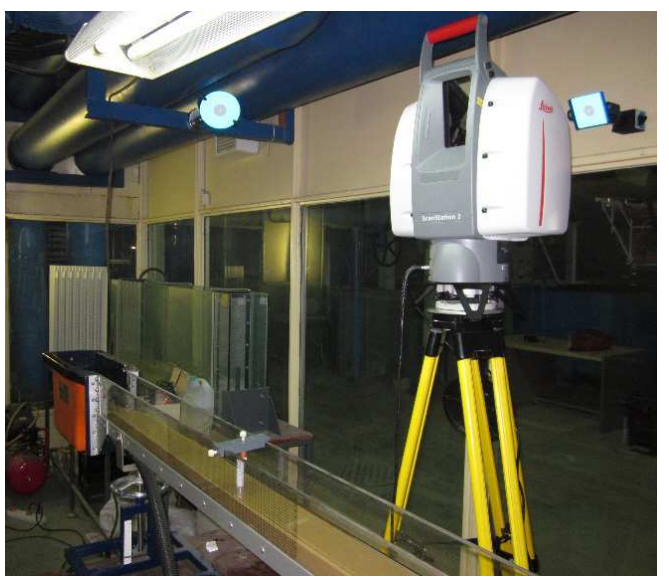

Figure 6. Leica ScanStation 2 terrestrial laser scanner position (Craciun, 2014)

In the present experiment, in order to obtain the spatial information, the position of the unit device has been chosen so as to obtain a maximum coverage and precision (figure 7), based on both the incidence angle and the distance between the camera and object.

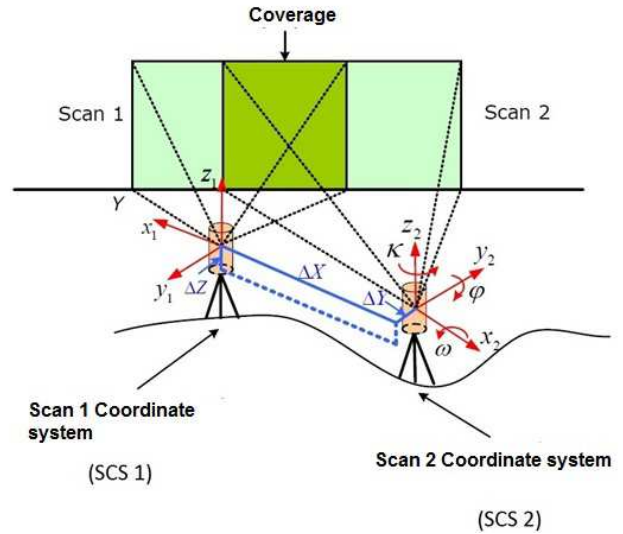

Figure 7. The overlapping of 2 adjacent stations (Reshetyuk, 2009)

During data achievement process a special attention was given to the variety of parameters that describe the acquisition procedure such as: horizontally and vertically scanning angles, area to be covered in a scan, resolution, diameter and divergence of the laser beam etc. 
Given that the region to be scanned had a high curvature, the object definition required a large number of points and thus a larger resolution. The area selected for scanning has been limited to a portion of the channel where pier presences influence bed river shape (figure 8 ). Thus, upstream scan pier made up to $10 \mathrm{~cm}$ and downstream, to about $40 \mathrm{~cm}$ (Craciun, Anton, 2013).

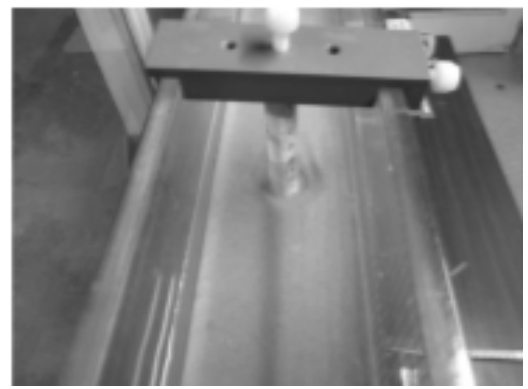

Figure 8. The area of interest (Craciun, 2014)

The scanning process was fully automated. The resolution of scanning was $2 \mathrm{~mm}$. Because of the fact that the object of interest was scanned from three different stations at the end of each scan was made on the computer a visual check of results, in order to see if important parts of the scanned object are missing. A total of $6.71 \mathrm{~GB}$ data have been acquired and referred to an internal coordinate system.

\subsection{Data processing}

The data processing was realized after physical scanning, using Leica Cyclone 6.0 software.

The data were stored in a database, organized into three ScanWorlds, one for each acquisition position.

The first step was to register point clouds obtained from different stations and unifying the point cloud. This was done using the software tools provided by Cyclone. The registration process precision was $1 \mathrm{~mm}$. This process led to the creation of a single cloud of points in a single ScanWorld from the three sets of the original data (figure 9).

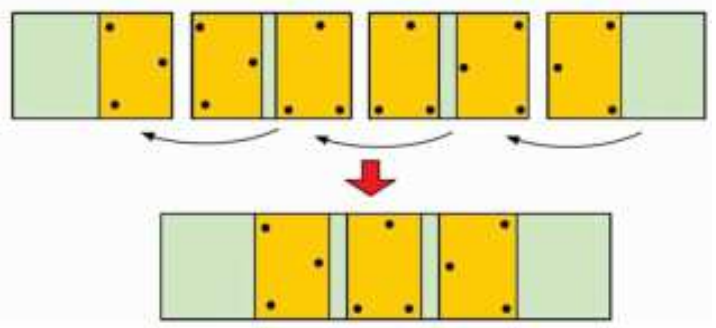

Figure 9. Registration process (Reshetyuk, 2009)

During the scanning process, the device collected all the details that appeared in the visual field, but not all of them were necessary (figure 10).

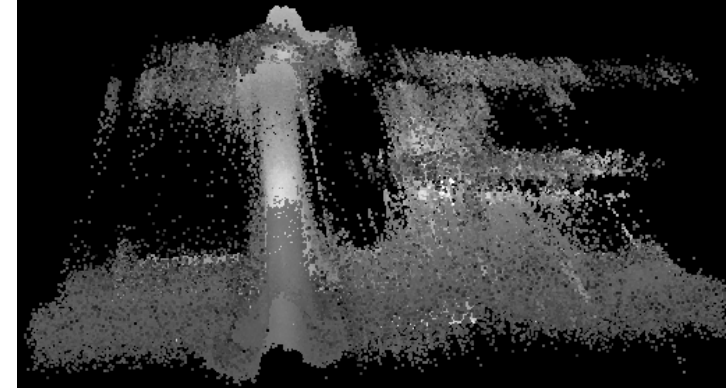

Figure 10. The registered point cloud

Thus, the second phase was data filtering, i.e. the removal of unwanted information before creating the final product (figure 11). This process was mainly a manual process.

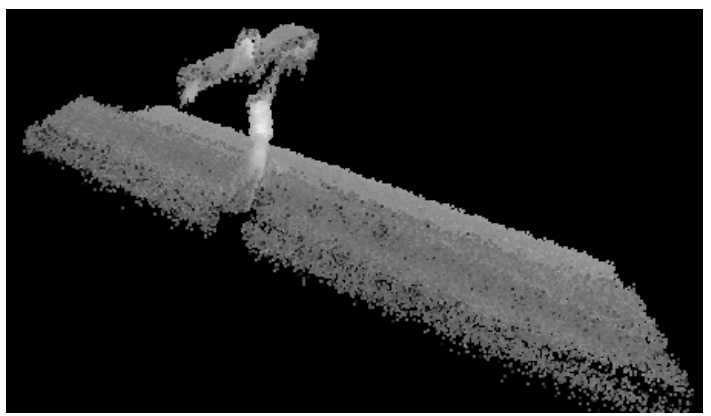

Figure 11. The filtered point cloud

The obtained data were used in CAD packages. For each situation we extracted a section bounded by two vertical planes. One is the vertical median longitudinal plane of the channel, and the other is parallel with the first and settled at $5 \mathrm{~cm}$ left in the direction of water flow.

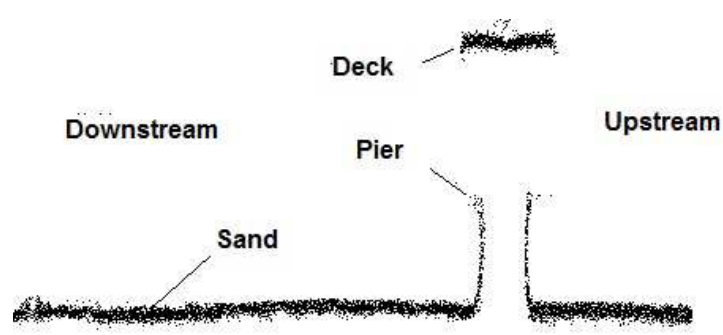

Figure 12. Longitudinal section through the channel - the start of the experiment (Craciun, 2014)

In figure 12 is shown the initial state, when $t=0$ before the start of the experiment. The figure is a side view perpendicular to the channel. In this case the scanner has been placed on the left side of the channel in the direction of water flow, about $70 \mathrm{~cm}$ above the channel.

Before entering the third stage flow after scour stabilization, a scan of bed channel was performed - figure 13 .

Scour value was $12.9 \mathrm{~mm}$ shares resulting from the difference of two points, one immediately upstream of the pier $(-0.7744 \mathrm{~m})$, and the second in the upstream in the area influenced by the 
presence of the obstacle $(-0.7615 \mathrm{~m})$. The points' levels are relative to the internal coordinate system scanner.

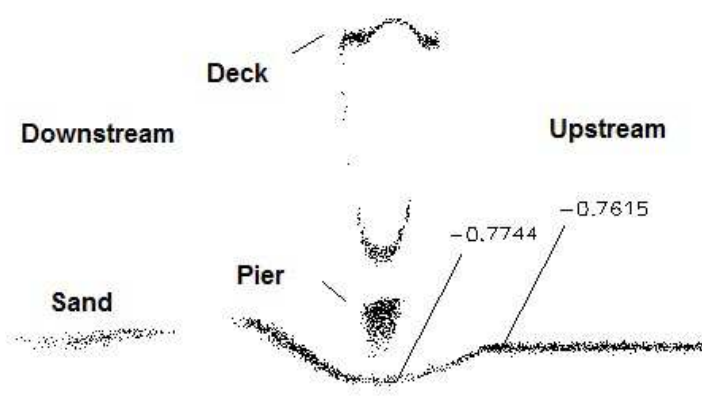

Figure 13. Longitudinal section through the middle of the channel after scour stabilizing - flow step 2 (Craciun, 2014)

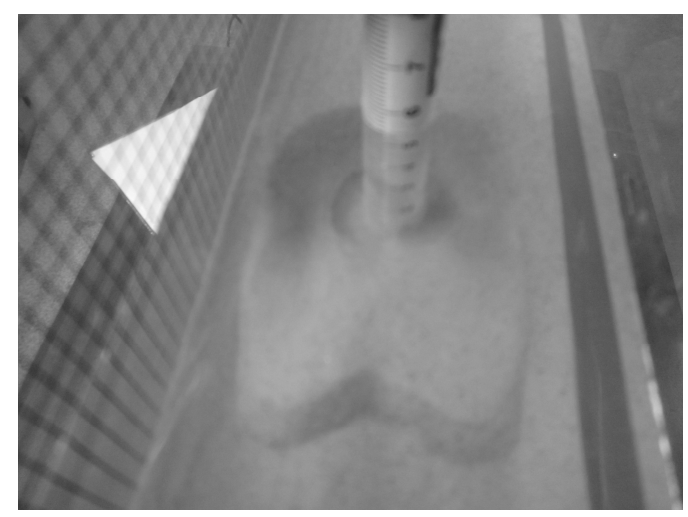

Figure 14. View from downstream (Craciun, 2014)

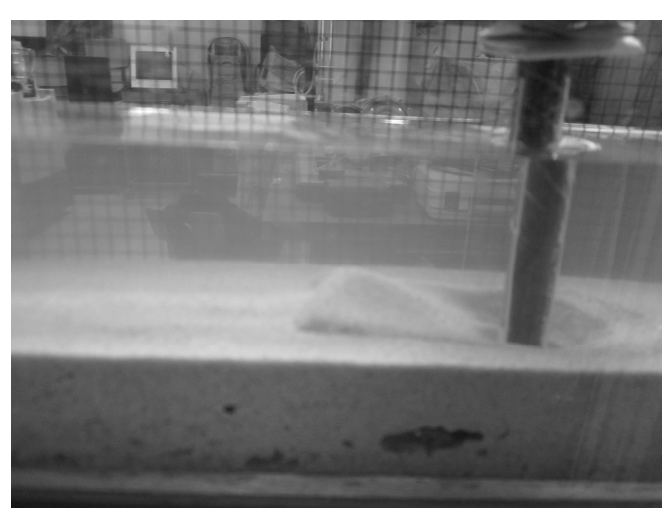

Figure 15. Left side view (Craciun, 2014)

The maximum value of scour (figure 14, 15), measured after stabilization, corresponding to the third step of flow, without going through lower levels, is shown in figure 16.

Scour results reading levels on $\mathrm{z}$ axis for points upstream of pier, in the area influenced by the presence of the obstacle (-0.7505), and points located immediately upstream of the pier (-0.7696). Points cloud coordinates are given in meters and they are reported to the internal coordinate system of the scanner. The value of scour $19 \mathrm{~mm}$ results from the difference between the two levels.

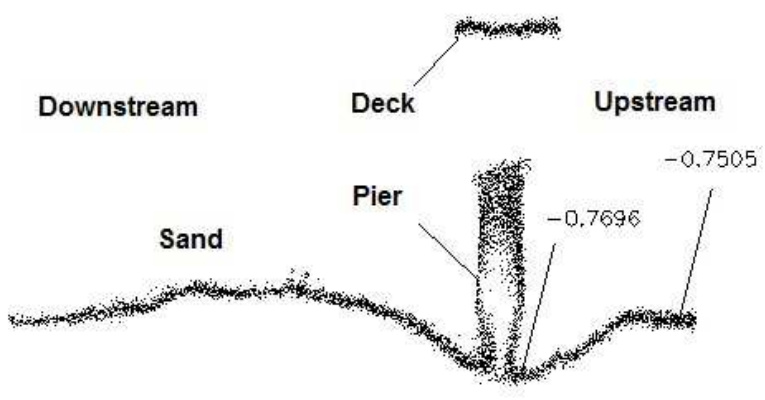

Figure 16. Longitudinal section through the center of channel after scour stabilization - maximum flow (Craciun, 2014)

In the laboratory experiments, scours were measured by readings the levels on a ruler attached to pier. Also, numerical calculations were performed to determine scour, both based on the departmental normative for hydraulic sizing of bridges and HEC-RAS program (Hydrologic Engineering Center, 2008). Observations and laboratory results serve to calibrate the numerical model for determining the scours.

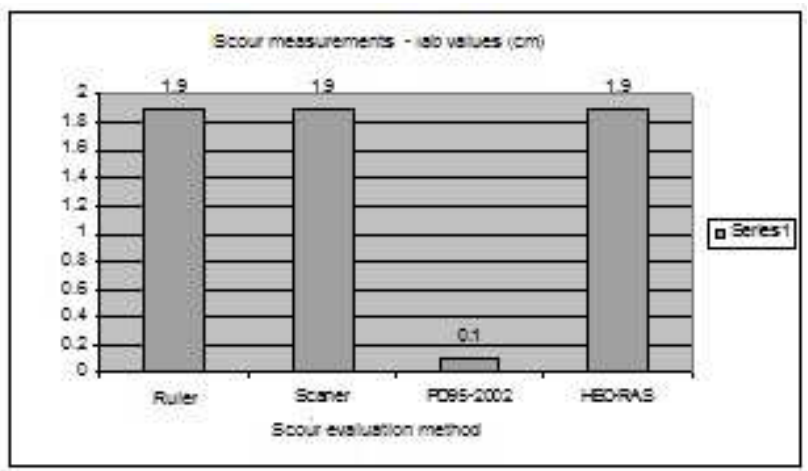

Figure 17. Determination of scour in laboratory experiments (Craciun, 2014)

The measurements made by the scanner are close to those obtained from readings on ruler, as you can see in figure 17.

Clear water without solid sediment transport was used in all experiments, and the current had no major turbulence. In this case, the results obtained using scanning station was conclusive, valid and satisfactory.

\section{CONCLUSION}

The scanners used as an advanced tools for measurement, gives detailed information both quantitatively and qualitatively.

The results are easy to process because they can be placed in a specialized program that facilitates processing. This leads to better measure of evolution and changes that occur in the bed of a river.

Also, the time required contouring of river bed is low compared with the conventional method, which is based on the use of topographic stations. Another advantage is that the device, 
settled in a convenient location, collect information from hard to reach places and with minimum risk to user.

Scans were performed in laboratory using clear water. The good results obtained in the laboratory make it possible to use the device in nature. In this case it must take into account the possible presence of water float and a high transport of sediments, which may impossible to obtain satisfactory results.

The results have limited applicability to the conditions imposed by the channel used in laboratory and the assumptions underlying the experiments.

\section{REFERENCES}

Armfield, 2010. Sediment Transport Demonstration Channel Technical Teaching Equipment, http://www.armfield.co.uk (view at february 2015).

Beg, M., Beg, S., 2013. Scour reduction around bridge piers: a review. In International Journal of Engineering Inventions, Vol. 2, issue 7, pp. 07-15.

Briaud, J.L., Ting, F., Chen, H.C., Gudavalli, R., Perugu, S.,Wei, G., 1999. SRICOS: prediction of scour rate in cohesive soils at bridge piers. In Journal of Geotechnical and Geoenvironmental Engineering Vol. 125, no. 4, pp 237 - 246.

Cao, Y., Bai, Y., Wang, J., Liao, S., Xu, D., 2015. Prediction of scour depth arround offshore pipelines in the South China Sea. In Journal of Marine Science and Application, Vol. 14, issue 1, pp 83-92.

Craciun, E.G., 2014. Analysis of scour phenomenon around profiled piers placed in a stream. PhD. Theses, Technical University of Civil Engineering, Bucharest, Romania.

Craciun, E.G., Anton, A. 2013. Experimental and Numerical Evaluation of Local Scour around a Bridge Pier. In Journal of Engineering Geology and Hydrogeology, Vol. 1, issue 1, pp. 17.

Esmaieli, T., Dehghani, A., A., Zahiri, A., R., Suzuki, K., 2009. 3D numerical simulation of scouring around bridge piers (case study: bridge 524 crosses the Tanana river). In World Academy of Science, Engineering and Technology, Vol. 58, pp. 10281032.

Forde, M.C., McCann, D.M., Clark, M.R., Broughton, K.J., Fenning, P.J., Brown, A., 1999. Radar measurement of bridge scour. In NDT\&E International, Vol. 32, issue 8, pp. 481-492.

Hamill, L., 1998. Bridge hydraulics. London: E\& FN Spon.

Hydrologic Engineering Center, 2008. HEC-RAS River Analysis System. Applications Guide ver. 4.0, U.S. Army Corps of Engineers, Davis, CA.

Jocea, A.F., 2005. Terrestrial 3D Laser Scanning Applications in Civil Engineering Projects. Diploma Theses, Universitat der Bundeswehr, Munchen, Germania.
Jocea, A., Calin, A., Plopeanu, M., Dumitru, P., Badescu, O., 2013. Static Terrestrial 3D Laser Scanning applications in Civil Engineering Projects.

In SGEM Conference Proceedings, Albena, Bulgaria, Vol. 2, pp $413-420$.

Leica Geosystems AG, Heerbrugg, Switzerland, www.leicageosystems.com/hds (view at february 2015).

Olsen, N. R. B., Jimenes, O. F., Abrahamsen, A., Lovoll, A., 1999. 3D CFD modeling of water and sediment flow in a hydropower reservoir. In International Journal of Sediment Research., vol. 14, no. 1.

Prendergast, L.J, Gavin, K., 2014. A review of bridge scour monitoring techniques. In Journal of Rock Mechanics and Geotechnical Engineering, Vol. 6, pp. 138 - 149.

Reshetyuk, Y., 2009. Self-calibration and direct georeferencing in terrestrial laser scanning. Doctoral thesis in Infrastructure, Geodesy. Royal Institute of Technology (KTH), Department of Transport and Economics, Division of Geodesy, Stockholm, Sweden

Staiger, R., 2007. Terrestrial Laserscanning - Scanners and Methods. Presentation at INTERGEO East, Sofia, Bulgaria, 1 2 March. 